\title{
Obstrução e uniformidade de aplicação em sistemas de irrigação por gotejamento aplicando-se efluente da suinocultura
}

\author{
Rafael O. Batista', Rubens A. Oliveira ${ }^{2}$, Delfran B. dos Santos ${ }^{3}$, \\ Adriana de F. M. Oliveira ${ }^{1}$, Carlos A. V. de Azevedo ${ }^{4}$ \& Salomão de S. Medeiros ${ }^{5}$
}

\begin{abstract}
RESUMO
Neste trabalho buscou-se analisar o efeito de diferentes manejos de água residuária de suinocultura e de água de abastecimento na obstrução de emissores e na uniformidade de aplicação de sistemas de irrigação por gotejamento. O experimento foi realizado na Universidade Federal de Viçosa (UFV) e montado em esquema de parcelas subsubdivididas tendo, nas parcelas, os manejos (1E3A - uma hora de aplicação de efluente mais três horas de aplicação de água limpa, 2E2A - duas horas de aplicação de efluente mais duas horas de aplicação de água limpa, 3E1A - três horas de aplicação de efluente mais uma hora de aplicação de água limpa e 4E - quatro horas de aplicação de efluente), nas subparcelas os tipos de gotejador (G1, G2 e G3) e, nas subsubparcelas, os tempos das avaliações $(0,20,40,60,80,100,120,140$ e $160 \mathrm{~h})$ em delineamento inteiramente casualizado com três repetições. Os resultados obtidos indicaram que na água residuária de suinocultura as características sólidos suspensos, ferro total e população bacteriana, representaram risco severo de entupimento de gotejadores e que houve redução elevada da uniformidade de aplicação de efluente quando o tempo de aplicação de água residuária foi igual ou superior ao da água de abastecimento.
\end{abstract}

Palavras-chave: água residuária, desempenho, gotejadores

\section{Clogging and uniformity of application in drip irrigation systems operating with swine wastewater}

\begin{abstract}
This study aimed to evaluate the effect of different managments of swine wastewater and clean water on clogging of emitters and application uniformity of drip irrigation systems. The experiment was conducted in the experimental area of the Federal University of Viçosa (UFV) and mounted in a split split-plots, having in the plots the managments (1E3A - one hour of application of effluent and three hours of application of clean water, 2E2A - two hours of application of effluent and two hours of application of clean water, 3E1A - three hours of application of effluent and one hour of application of clean water and $4 \mathrm{E}$ - four hours of application of effluent), in the subplots the types of drippers (G1, G2 and G3) and in the subsubplots the evaluation times $(0,20,40,60,80,100,120,140$ and $160 \mathrm{~h})$ in a completely randomized design with three replications. The results indicated that in the swine wastewater the characteristics suspended solids, total iron and bacterial population represented severe risk of clogging of drippers; and that there was a high reduction of the uniformity of application of effluent when the time of application of wastewater is equal to or greater than the water supply.
\end{abstract}

Key words: wastewater, performance, drippers

'DACT/UFERSA. Av. Presidente Dutra, 572, Costa e Silva, CEP 59625-900, Mossoró, RN. E-mail: rafaelbatista@ufersa.edu.br; oliveira.adrianamendes@gmail.com

${ }^{2}$ DEA/UFV. Av. P H Rolfs, s/n - Campus Universitário, CEP 36570-000, Viçosa, MG. E-mail: rubens@ufv.br

${ }^{3}$ IFbaiano. Estrada da Igara, s/n - Zona Rural, CEP 48970-000, Senhor do Bonfim, BA. E-mail: delfran.batista@gmail.com

${ }^{4}$ UAEA/UFCG. R. Aprígio Veloso, 882 - Bodocongo, CEP 58109-900, Campina Grande, PB. E-mail: carlos.agriambi@gmail.com

${ }_{5}^{5}$ INSA. Av. Francisco Lopes de Almeida, s/n - Bairro Serrotão, CEP 58429-970, Campina Grande, PB. E-mail: salomao@insa.gov.br 


\section{INTRODUÇÃO}

No contexto nacional a importância da suinocultura reside não só no grande número de criadores envolvidos mas também no volume de empregos gerados, direta e indiretamente e pela capacidade de produzir grande quantidade de proteína de alta qualidade em área reduzida e em curto espaço de tempo, em comparação com outras espécies de animais de médio e grande porte (Cabral et al., 2011).

A atividade suinícola integrada à agroindústria é desenvolvida em sistemas de confinamento cujo manejo de higienização das instalações, associado às fezes e à urina dos animais, resulta em água residuária. Quando manejados inadequadamente esses resíduos podem degradar o ambiente (Maggi et al., 2011).

A utilização de águas residuárias de suinocultura na agricultura é uma alternativa para controle da poluição das águas superficiais e subterrâneas, além da disponibilização de água e fertilizantes para as culturas, ciclagem de nutrientes e aumento na produção agrícola. Entretanto, para que isto possa tornar-se prática viável é preciso aperfeiçoar as técnicas de tratamento, aplicação e manejo de águas residuárias de suinocultura (Drumond et al., 2006).

O método de irrigação localizada é usado para a aplicação de águas residuárias em razão da elevada eficiência de aplicação do efluente e do baixo risco de contaminação, tanto do produto agrícola quanto de operadores no campo (Dazhuanget al., 2009; Batista et al., 2009; Duran-Ros et al., 2009).

Nos sistemas de irrigação localizada, entretanto, os emissores apresentam alta suscetibilidade ao entupimento. A sensibilidade ao problema de entupimento varia com as características do gotejador e com a qualidade da água relacionada aos aspectos físicos, químicos e biológicos (Santos et al., 2003; Silva et al., 2012).

A formação de biofilme resultante da interação entre mucilagens bacterianas e partículas orgânicas e inorgânicas tem sido a principal causa de entupimento de gotejadores que operam com águas residuárias (Batista et al., 2010).

$\mathrm{O}$ entupimento de gotejadores prejudica o funcionamento geral do sistema de irrigação afetando suas características de operação e exigindo manutenções mais frequentes. Comumente, a obstrução diminui a uniformidade de aplicação de efluente de sistemas de irrigação localizada (Liu \& Huang, 2009).

Para minimização do entupimento de gotejadores são recomendadas diversas técnicas. Entre as práticas mais aceitas ambientalmente se incluem a sedimentação, a filtração, o aumento da pressão de serviço e a limpeza das linhas laterais com água (Puig-Bargues et al., 2010). Considerando que o uso de águas residuárias de suinocultura na agricultura é incipiente no Brasil, torna-se indispensável a criação de novas tecnologias de prevenção do entupimento de gotejadores, com custo acessível ao produtor e baixo risco à saúde humana, às plantas cultivadas e ao ambiente.

O presente trabalho tem por objetivo analisar o efeito de distintos manejos com a aplicação de proporções de água residuária de suinocultura e água de abastecimento local na uniformidade de aplicação de efluente de sistemas de irrigação por gotejamento.

\section{Material e MÉTodos}

O presente trabalho foi realizado na Unidade-Piloto de Tratamento e Aplicação Localizada de Água Residuária de Suinocultura (UTARS) do Departamento de Engenharia Agrícola (DEA) pertencente à Universidade Federal de Viçosa (UFV) em Viçosa, MG, Brasil.

A água residuária de suinocultura foi submetida aos processos de tratamento por sedimentação, degradação anaeróbia e filtração, para possibilitar operação das unidades de aplicação de efluente com riscos mínimos de entupimento físico. Na UTARS o tempo de retenção hidráulica foi de $339 \mathrm{~h}$ e a vazão de $15,12 \mathrm{~m}^{3} \mathrm{~d}^{-1}$ obtida de um plantel de 420 suínos.

A plataforma de testes foi construída em alvenaria, nas dimensões de 3,4 $\mathrm{m}$ de largura por 18,0 $\mathrm{m}$ de comprimento, com declividade transversal de $2 \%$ (Figura 1). Uma canaleta foi construída ao longo da lateral mais baixa da plataforma com a finalidade de se coletar e retirar, da plataforma, a água de abastecimento e água residuária aplicada pelos gotejadores.

A unidade de controle para bombeamento da água residuária de suinocultura foi constituída de um reservatório de 7,0 $\mathrm{m}^{3}$, uma peneira com tela metálica de $47 \mu \mathrm{m}$ e um conjunto motobomba de $3 \mathrm{cv}$ (Figura 1A). A outra unidade de controle para o bombeamento da água de abastecimento foi composta de um reservatório de $6,0 \mathrm{~m}^{3}$, um conjunto motobomba de 3 cv e um filtro de discos com abertura de $130 \mu \mathrm{m}$ (Figura 1B).

$\mathrm{Na}$ plataforma foram montadas quatro unidades de fertirrigação, em que cada uma possuía uma válvula reguladora de pressão de $105 \mathrm{kPa}$, uma linha de derivação de PVC com diâmetro nominal de $32 \mathrm{~mm}$ e nove linhas laterais de polietileno.

Em cada unidade de aplicação de efluente foram testados três tipos de gotejador, apresentados na Tabela 1. Para cada tipo de gotejador foram instaladas, na linha de derivação, três linhas laterais com $18 \mathrm{~m}$ de comprimento, em nível (Figura 1C). Em todas as linhas laterais foram marcados 22 emissores para medição da vazão (Figura 1D).

Quatro manejos de aplicação de efluente e da água de abastecimento local, cada um em determinada unidade de fertirrigação, descritos a seguir:

1E3A - uma hora de aplicação do efluente seguida de três horas de aplicação com água de abastecimento;

2E2A - duas horas de aplicação do efluente seguidas de duas horas de aplicação com água de abastecimento;

3E1A - três horas de aplicação do efluente seguidas de uma hora de aplicação com água de abastecimento; e

$4 \mathrm{E}$ - quatro horas de aplicação do efluente.

$\mathrm{O}$ experimento foi montado em esquema de parcelas subsubdivididas tendo, nas parcelas, os níveis (1E3A, 2E2A, 3E1A e 4E), nas subparcelas os tipos de gotejador (G1, G2 e G3) e nas subsubparcelas os tempos das avaliações $(0,20,40$, $60,80,100,120,140$ e $160 \mathrm{~h}$ ) em delineamento inteiramente casualizado, com três repetições.

Durante os ensaios as unidades de fertirrigação funcionaram quatro horas por dia, até completar $160 \mathrm{~h}$. Neste período foram determinadas as vazões dos gotejadores e as características física, química e biológica do efluente e da água de abastecimento.

Através do uso de válvulas reguladoras de pressão nas quatro unidades de aplicação de efluente, a pressão de serviço 
A.

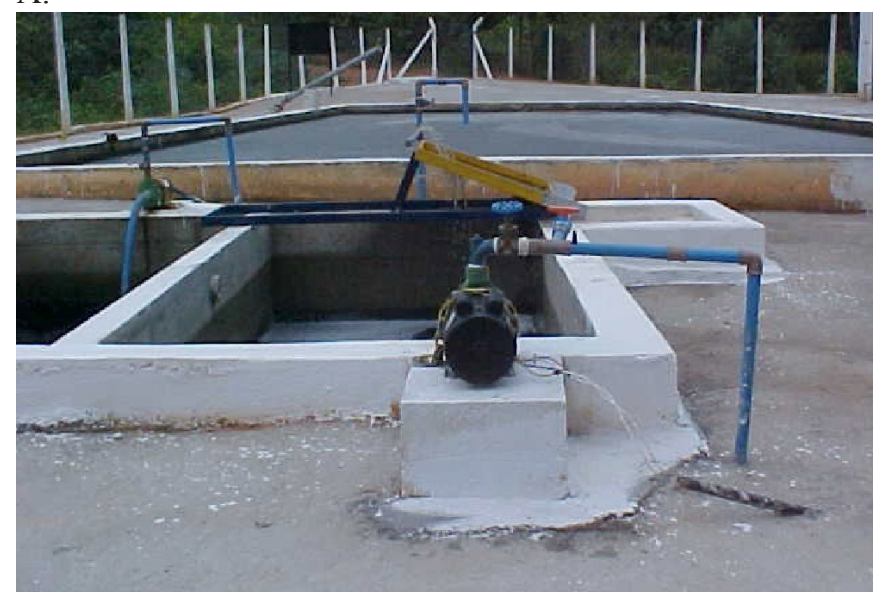

C.

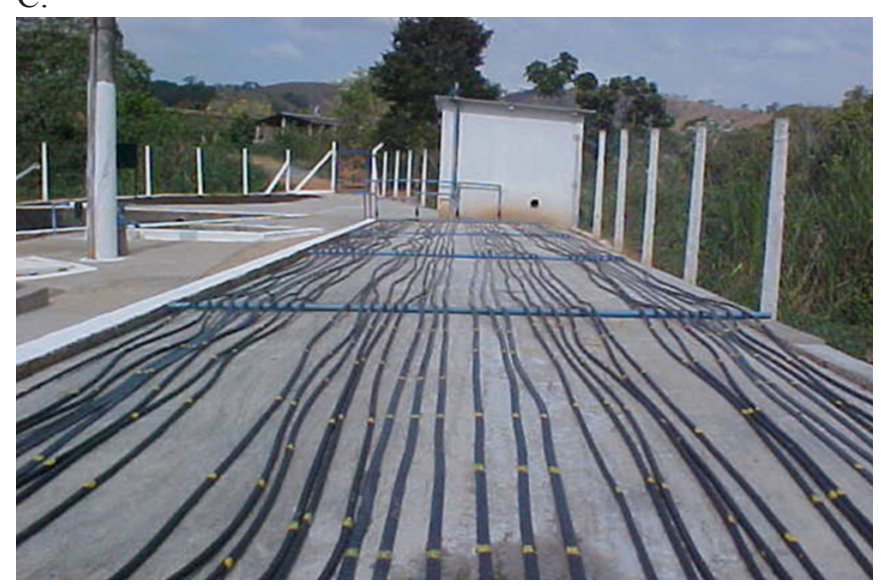

B.

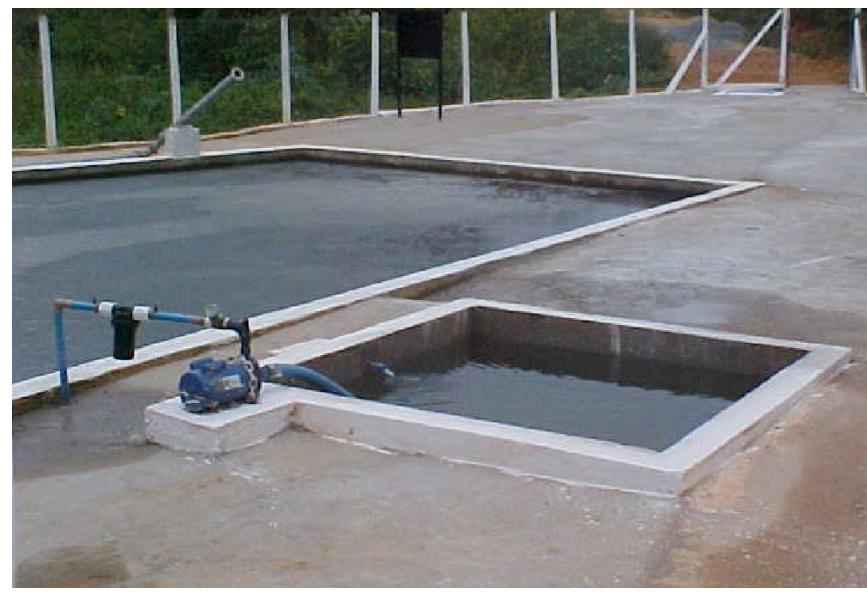

D.

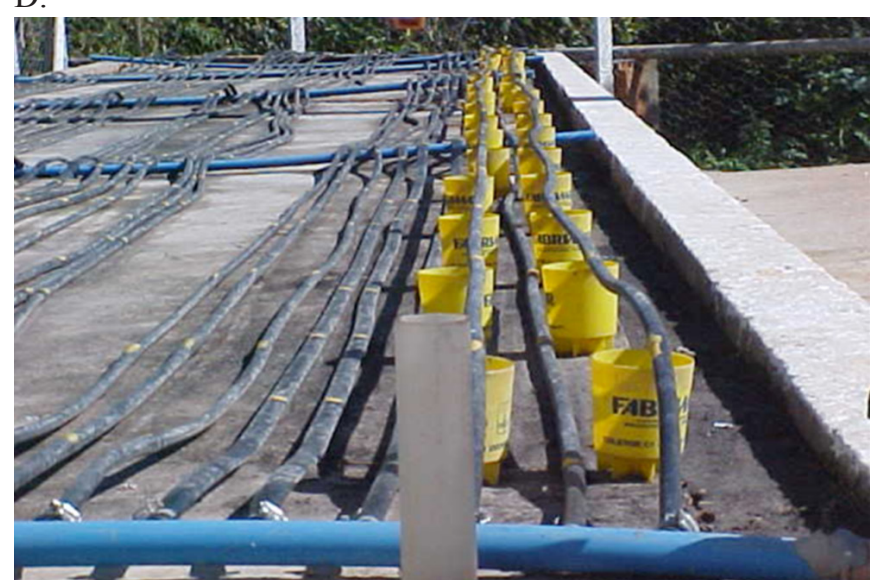

Figura 1. Bancada experimental destacando-se as unidades de controle para bombeamento de água residuária de suinocultura (A), a água de abastecimento (B), a plataforma de testes (C) e o ensaio para medição de vazão (D)

Tabela 1. Características dos gotejadores $(G)$ utilizados nos ensaios: vazão nominal $(\mathrm{Q})$, área do orifício $(\mathrm{A})$, comprimento do labirinto $(\mathrm{L})$, coeficiente de variação de fabricação $\left(\mathrm{CV}_{\mathrm{f}}\right)$ e faixa de pressão recomendada $(\mathrm{P})$

\begin{tabular}{|c|c|c|c|c|c|}
\hline G & $\begin{array}{c}Q \\
\left(L h^{-1}\right)\end{array}$ & $\begin{array}{c}\text { A } \\
\left(\mathrm{mm}^{2}\right)\end{array}$ & $\begin{array}{c}\mathrm{L} \\
(\mathrm{mm})\end{array}$ & $\begin{array}{l}\mathrm{CV}_{\mathrm{f}} \\
(\%)\end{array}$ & $\begin{array}{c}P \\
(\mathrm{kPa})\end{array}$ \\
\hline G1 & 2,00 & $4,45^{\prime}$ & 327 & $\leq 3$ & $80-300$ \\
\hline $\mathrm{G} 2$ & 1,70 & 1,86 & 176 & $\leq 3$ & $40-100$ \\
\hline G3 & 3,60 & 2,54 & 44 & $\leq 4$ & $80-350$ \\
\hline
\end{tabular}

foi mantida em $105 \pm 5 \mathrm{kPa}$ e medida diariamente com

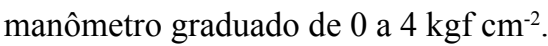

Realizou-se a medição de vazão nos 22 gotejadores identificados de todas as linhas laterais das unidades de aplicação de efluente. A vazão de cada gotejador foi determinada coletando-se o volume aplicado durante três minutos. O desempenho dos sistemas foi avaliado a cada $20 \mathrm{~h}$, durante o período de aplicação do efluente, utilizando-se a Eq. 1.

$$
\mathrm{CUD}=\frac{\mathrm{Q}_{25 \%}}{\mathrm{Q}_{\mathrm{med}}} 100
$$

em que:

CUD - coeficiente de uniformidade de distribuição, \%

$\mathrm{Q}_{25 \%}$ - valor médio dos $25 \%$ menores valores de vazões dos gotejadores, $\mathrm{L} \mathrm{h}^{-1}$
$\mathrm{Q}_{\mathrm{med}}$ - vazão média dos gotejadores, $\mathrm{L} \mathrm{h}^{-1}$

As características física, química e biológica da água residuária de suinocultura e da água de abastecimento foram avaliadas a cada 20 e $80 \mathrm{~h}$ de funcionamento das unidades de fertirrigação, respectivamente, em conformidade com as recomendações do Standard Methods (APHA, 2005).

No Laboratório de Qualidade da Água do Departamento de Engenharia Agrícola da UFV foram medidos os valores de $\mathrm{pH}$, Demanda Bioquímica de Oxigênio $\left(\mathrm{DBO}_{5}\right)$, sólidos suspensos (SS) e sólidos dissolvidos (SD); enquanto nos Laboratórios de Matéria Orgânica e Resíduos e de Espectrofotometria Atômica, ambos do Departamento de Solos da UFV se determinaram as concentrações de ferro total $(\mathrm{Fe})$, manganês total $(\mathrm{Mn})$, cálcio $\left(\mathrm{Ca}^{2+}\right)$ e magnésio $\left(\mathrm{Mg}^{2+}\right)$.

As populações de bactérias (PB) foram quantificadas no Laboratório de Microbiologia de Alimentos do Departamento de Microbiologia da UFV sendo que os resultados foram expressos em unidades formadoras de colônia por mililitro (UFC mL $\mathrm{mL}^{-1}$ ).

Os dados foram submetidos à análise de variância, ao teste de média e à análise de regressão. $\mathrm{Na}$ análise de variância empregou-se o teste $\mathrm{F}$ no nível de até $5 \%$ de probabilidade. As médias foram comparadas utilizando-se o teste de Tukey a 5\% de probabilidade. Os modelos de regressão foram escolhidos com base na significância dos coeficientes de regressão 
utilizando-se o teste t num nível de até $10 \%$, no coeficiente de determinação e no processo em estudo.

Na realização das análises estatísticas utilizou-se o programa computacional SAEG 9.1 (Ribeiro Júnior \& Melo, 2008)

\section{Resultados E Discussão}

$\mathrm{Na}$ Tabela 2 se encontram as características físico-químicas e microbiológicas da água residuária de suinocultura (ARS) e da água limpa (AL) utilizadas nos ensaios com sistemas de irrigação por gotejamento, além dos riscos de entupimento de emissores. As características SS, Fe e PB da ARS, representam risco severo de entupimento de gotejadores; enquanto para $\mathrm{pH}, \mathrm{SD}, \mathrm{Mn}$ e $\mathrm{Mg}^{2+}$ tal risco foi moderado e, para $\mathrm{Ca}^{2+}$, baixo (Nakayama \& Bucks, 1991; Capra \& Scicolone, 1998).

Comparando tais resultados (Tabela 2) notam-se menores riscos de obstrução de gotejadores proporcionados pela água residuária de suinocultura primária em relação ao esgoto doméstico tratado em sistema de lodo ativado (Liu \& Huang, 2009). Esses autores afirmaram, também, que somente a característica $\mathrm{pH}$ representou risco severo de obstrução de gotejadores; segundo Libânio (2005) altos valores de $\mathrm{pH}$ podem originar problemas de incrustação em tubulações.

Para as características SD, $\mathrm{Fe}$ e $\mathrm{Mg}^{2+}$ tal risco foi moderado e, para as características $\mathrm{SS}, \mathrm{Mn}, \mathrm{Ca}^{2+} \mathrm{ePB}$, o risco de obstrução de gotejadores foi classificado como baixo.

No caso da $\mathrm{AL}$, o $\mathrm{pH}$ representa risco moderado de obstrução de gotejadores enquanto para SD, $\mathrm{Ca}^{2+}, \mathrm{Mg}^{2+}$ e PB tal risco foi baixo (Tabela 2). As demais características SS, Fe e Mn da AL não representam risco de obstrução de gotejadores. Tais resultados corroboram com outros obtidos com sistemas de irrigação por gotejamento abastecido com água limpa visto que houve risco moderado de entupimento de gotejadores para o pH e baixo risco de obstrução para as características SS, SD, $\mathrm{Fe}, \mathrm{Mn}, \mathrm{Ca}^{2+}, \mathrm{Mg}^{2+}$ e PB (Liu \& Huang, 2009).

Uma das formas de se prevenir o entupimento de sistemas de irrigação localizada consiste no tratamento preliminar da água de irrigação fazendo-se uso de sistema com aeração, decantação e filtragem (Lemos Filho et al., 2011). Na Figura 2 estão apresentados os valores dos coeficientes de uniformidade de distribuição (CUD) das subunidades dotadas dos gotejadores G1, G2 e G3, submetidas ao manejo de aplicação da água residuária de suinocultura e da água de abastecimento (1E3A, 2E2A, 3E1A e 4E).
A.

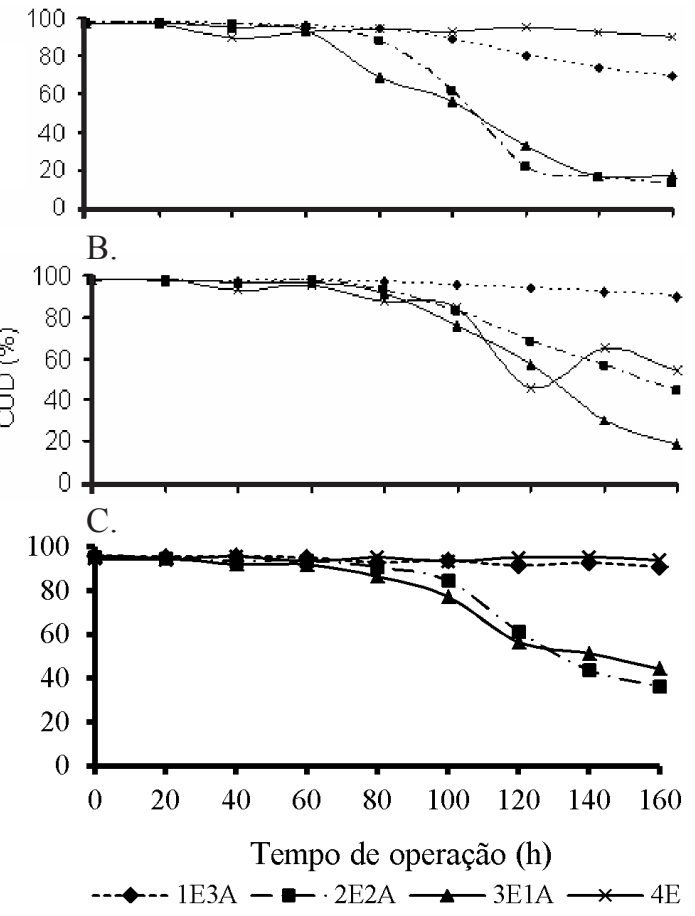

Figura 2. Coeficiente de uniformidade de distribuição (CUD) ao longo do tempo de funcionamento, nas subunidades com gotejador G1 (A), G2 (B) e G3 (C) submetidas aos manejos de aplicação de efluente e da água de abastecimento $1 \mathrm{E} 3 \mathrm{~A}, 2 \mathrm{E} 2 \mathrm{~A}, 3 \mathrm{E} 1 \mathrm{~A}$ e $4 \mathrm{E}$

Os valores de CUD das subunidades com gotejador G1 submetidas aos manejos 1E3A, 2E2A, 3E1A e 4E nos tempos de funcionamento inicial e $160 \mathrm{~h}$, foram de 97,05 e $69,57 \%$; 97,40 e $13,08 \%$; 97,58 e $17,49 \%$; 97,93 e $90,79 \%$, respectivamente (Figura 2A).

No tempo de funcionamento inicial os valores de CUD das subunidades foram superiores a $90 \%$; classificados, portanto, como excelentes (Merriam \& Keller, 1978). No tempo de funcionamento de $160 \mathrm{~h}$ os valores de CUD das subunidades submetidas aos manejos 1E3A, 2E2A e 3E1A foram inferiores a $70 \%$ sendo então classificados como ruins enquanto o valor de CUD da subunidade submetida ao manejo $4 \mathrm{E}$ foi superior a $90 \%$, mantendo a classificação excelente. Comparando os tempos de funcionamento inicial e $160 \mathrm{~h}$, constatou-se que as

Tabela 2. Características físico-químicas e microbiológicas da água residuária de suinocultura (ARS) e da água de abastecimento (AL) utilizadas nos ensaios experimentais e os riscos de entupimento de gotejadores

\begin{tabular}{|c|c|c|c|c|c|c|}
\hline \multirow[b]{2}{*}{ Características } & \multirow[b]{2}{*}{ ARS } & \multicolumn{2}{|c|}{ Risco de entupimento de gotejadores } & \multirow[b]{2}{*}{ AL } & \multicolumn{2}{|c|}{ Risco de entupimento de gotejadores } \\
\hline & & $\begin{array}{c}\text { Nakayama \& Bucks } \\
\text { (1991) }\end{array}$ & $\begin{array}{c}\text { Capra \& Scicolone } \\
\text { (1998) }\end{array}$ & & $\begin{array}{c}\text { Nakayama \& Bucks } \\
\text { (1991) }\end{array}$ & $\begin{array}{c}\text { Capra \& Scicolone } \\
\text { (1998) }\end{array}$ \\
\hline $\mathrm{pH}^{*}$ & $7,54 \pm 0,14$ & Moderado & & $7,12 \pm 0,07$ & Moderado & \\
\hline $\mathrm{SD}^{*}\left(\mathrm{mg} \mathrm{L}^{-1}\right)$ & $1370 \pm 284,39$ & Moderado & & $54 \pm 9$ & Baixo & \\
\hline $\mathrm{Fe}^{\star}\left(\mathrm{mg} \mathrm{L}^{-1}\right)$ & $5,50 \pm 2,92$ & Severo & & $0 \pm 0$ & Nenhum & \\
\hline$M n^{*}\left(\mathrm{mg} \mathrm{L}^{-1}\right)$ & $0,84 \pm 0,76$ & Moderado & & $0 \pm 0$ & Nenhum & \\
\hline $\mathrm{DBO}_{5} *\left(\mathrm{mg} \mathrm{L}^{-1}\right)$ & $602 \pm 252,43$ & & & $10 \pm 0,59$ & & \\
\hline $\mathrm{PB}^{\star \star}\left(\mathrm{UFC} \mathrm{mL}^{-1}\right)$ & $9,7 \times 10^{5} \pm 5,62$ & Severo & & $1,5 \times 10^{3} \pm 2,71$ & Baixo & \\
\hline
\end{tabular}

SS - sólidos suspensos; SD - sólidos dissolvidos; Fe - ferro total; Mn - manganês total; $\mathrm{Ca}^{2+}$ - cálcio; $\mathrm{Mg}^{2+}$ - magnésio; DBO ${ }_{5}$ - demanda bioquímica de oxigênio; PB - população bacteriana; e UFC - unidades formadoras de colônias. *Média e desvio-padrão aritmético das características. **Média e desvio-padrão geométrico da característica 
reduções nos valores de CUD das subunidades submetidas aos manejos 1E3A, 2E2A, 3E1A e 4E foram de 28, 87, 82 e 7\%, respectivamente.

As subunidades com gotejador G2 submetidas aos manejos 1E3A, 2E2A, 3E1A e 4E apresentaram valores do CUD nos tempos de funcionamento inicial e $160 \mathrm{~h}$ de 97,51 e $89,69 \%$; 97,89 e $44,55 \%$; 98,14 e $18,78 \%$; 98,05 e $54,00 \%$, respectivamente (Figura 2B).

No tempo de funcionamento inicial todos os valores de CUD das subunidades foram superiores a $90 \%$ classificados, portanto, como excelentes, por Merriam \& Keller(1978). No tempo de funcionamento de $160 \mathrm{~h}$ o valor do CUD da subunidade submetida ao manejo 1E3A se mantinha dentro da faixa de 80 a $90 \%$, classificado como bom; enquanto os valores de CUD das subunidades submetidas aos manejos 2E2A, 3E1A e 4E foram menores que $70 \%$, classificados ruins. Comparando os tempos de funcionamento inicial e $160 \mathrm{~h}$. verificou-se que as reduções nos valores do CUD das subunidades submetidas aos manejos 1E3A, 2E2A, 3E1A e 4E foram de 8, 54, 81 e 45\%, respectivamente.

Os valores de CUD das subunidades com gotejador G3 submetidas aos manejos 1E3A, 2E2A, 3E1A e 4E nos tempos de funcionamento inicial e $160 \mathrm{~h}$, foram de 95,97 e $90,86 \%$; 95,52 e $36,29 \%$; 95,79 e $44,38 \%$; 94,64 e $94,00 \%$, respectivamente (Figura 2C).

No tempo de funcionamento inicial os valores de CUD das subunidades foram superiores a $90 \%$, classificados como excelentes (Merriam \& Keller, 1978). No tempo de funcionamento de $160 \mathrm{~h}$ os valores de CUD das subunidades submetidas aos manejos 1E3A e 4E foram superiores a $90 \%$, mantendo a classificação excelente; enquanto os valores de CUD das subunidades submetidas aos manejos 2E2A e 3E1A foram inferiores a $70 \%$, sendo classificados, assim como, ruins. Os valores de CUD das subunidades submetidas aos manejos 1E3A, 2E2A, 3E1A e 4E apresentaram reduções de 5, 62, 54 e $1 \%$, respectivamente, quando se estabeleceu comparação entre os tempos de funcionamento inicial e $160 \mathrm{~h}$. Os maiores níveis de entupimento ocorreram no gotejador G1 em relação a G2 e G3, devido ao maior comprimento de labirinto (Tabela 1) que favorece o desenvolvimento de biofilme nos trechos de menor velocidade de escoamento do efluente (Dazhuang et al., 2009).

Os resultados apresentados na Figura 2 corroboram com os encontrados por Rezende el al. (2000) que observaram diferenças significativas entre cinco modelos de gotejadores quando avaliados quanto à suscetibilidade ao entupimento de origem biológica.

Puig-Bargués et al. (2005) analisaram o desempenho de três unidades de irrigação por gotejamento, dotadas de gotejador não-autocompensante com vazão nominal de $1,9 \mathrm{~L}$ $\mathrm{h}^{-1} \mathrm{e}$ operando com esgoto doméstico tratado. Dois sistemas de irrigação, um com filtro de discos e outro com filtro de tela, ambos de $130 \mu \mathrm{m}$, foram abastecidos com esgoto doméstico secundário. $O$ terceiro sistema de irrigação constava de filtro de tela de $130 \mu \mathrm{m}$ e foi abastecido com esgoto doméstico terciário. Depois de $750 \mathrm{~h}$ de funcionamento das unidades de aplicação, os valores de CUD foram de 0,50 e 92\% para as unidades de irrigação aplicando efluente secundário filtrado em filtro de discos de $130 \mu \mathrm{m}$, efluente secundário filtrado em filtro de tela de $130 \mu \mathrm{m}$ e efluente terciário filtrado em filtro de tela de 130 $\mu \mathrm{m}$, respectivamente.

Batista et al. (2005) utilizaram sistemas de irrigação por gotejamento dotados de fitas gotejadoras com vazão nominal de $1,0 \mathrm{~L} \mathrm{~h}^{-1}$, para aplicação de água residuária da despolpa dos frutos do cafeeiro tratada em filtro orgânico e constataram drástica redução do CUD, que passou de 94 para $0 \%$ com 144 h de operação.

Capra \& Scicolone (2004) estudaram o desempenho hidráulico de sistemas de irrigação por gotejamento dotados de quatro tipos de gotejador não-autocompensantes, com vazão nominal de 3,8 a 4,0 $\mathrm{L} \mathrm{h}^{-1}$ e abastecidos com esgoto doméstico tratado durante $60 \mathrm{~h}$. Os referidos autores concluíram que os valores de CUD nos sistemas de irrigação oscilaram de 0 a 77\%.

Apesar do lançamento dos emissores autocompensantes no mercado, a avaliação dos sistemas de irrigação continua sendo um dos pontos de partida para o sucesso das lavouras. Portanto, sistemas bem dimensionados e uniformes na distribuição de água são fundamentais para a técnica da quimigação, o que resulta em aumento de produtividade (Nakayama \& Bucks, 1991).

No que se refere ao manejo da irrigação, uma consequência direta da baixa uniformidade de aplicação consiste no aumento do volume aplicado, isto é, o irrigante, ao constatar a diminuição da vazão média dos gotejadores pelo efeito do entupimento, aumenta o tempo de irrigação; logo, as plantas que receberam menor lâmina de irrigação passam a receber maior quantidade de água, de modo a atender às suas exigências hídricas. No entanto, as plantas que recebiam a lâmina adequada passam a ter problema de irrigação excessiva aumentando, então, a perda por percolação (López et al., 1992).

Ainda com relação às técnicas de manejo em sistemas de irrigação localizada utilizando-se água residuária (Figura 2) sugere-se que a cada $60 \mathrm{~h}$ de funcionamento do sistema de irrigação sejam adotadas práticas que resultem na redução e/ou prevenção de obstrução do sistema de irrigação (Cararo \& Botrel, 2007; Souza et al., 2006). Na Tabela 3 é apresentado o resumo da análise de variância dos valores de CUD das subunidades de fertirrigação, no esquema de parcelas subsubdivididas. A interação M x G x T foi significativa a $1 \%$ de probabilidade para a variável CUD, conforme apresentado na Tabela 3.

Tabela 3. Resumo das análises de variância da variável coeficiente de uniformidade de distribuição (CUD), no esquema de parcelas subsubdivididas

\begin{tabular}{lcc}
\hline Fonte de variação & Grau de & Quadrado médio \\
\cline { 3 - 3 } liberdade & CUD \\
Manejos distintos (M) & 3 & $8894,991^{\star \star}$ \\
Resíduo (a) & 8 & 169,171 \\
Tipo de gotejador (G) & 2 & $1669,081^{\star \star}$ \\
M x G & 6 & $1195,878^{\star \star}$ \\
Resíduo (b) & 16 & 85,498 \\
Tempo de funcionamento (T) & 8 & $10114,210^{\star \star}$ \\
M X T & 24 & $1471,913^{\star \star}$ \\
G X T & 16 & $321,427^{\star \star}$ \\
M X G X T & 48 & $238,580^{\star \star}$ \\
Resíduo (c) & 192 & 28,594 \\
\hline CV (\%) parcela & & 16 \\
CV (\%) subparcela & & 11 \\
CV (\%) subsubparcela & & 6 \\
\hline
\end{tabular}

** F significativo a 0,01 de probabilidade 
Notou-se ainda que os valores do coeficiente de variação desta variável na parcela, subparcela e na subsubparcela, foram de aproximadamente 16,11 e $6 \%$, respectivamente.

Em vista dos resultados das análises de variância, procedeuse ao desdobramento da interação M x G x T.

Estão apresentadas, na Tabela 4, as equações de regressão que melhor se ajustaram aos dados de CUD, em função do tempo de funcionamento, para cada nível de gotejador e dos distintos manejos adotados.

Tabela 4. Equações de regressão ajustadas à variável coeficiente de uniformidade de distribuição (CUD) em função dos tempos de funcionamento (T) para cada nível de gotejador (G) e os distintos manejos de efluente e água de abastecimento (MEA)

\begin{tabular}{|c|c|c|c|}
\hline $\mathbf{G}$ & MEA & Equação de regressão & $\overline{R^{2}}$ \\
\hline & 1E3A & CÛD $=97,038+0,0737^{\text {ns }} T-0,00161^{* *} T^{2}$ & 0,98 \\
\hline \multirow{2}{*}{ G1 } & 2 E2A & CÛD $=101,109+0,00815^{n S} T-0,00404^{* *} T^{2}$ & 0,91 \\
\hline & $\begin{array}{l}3 \mathrm{E} 1 \mathrm{~A} \\
4 \mathrm{E}\end{array}$ & $\begin{array}{l}\text { CÛD }=102,887+0,200^{* *} T-0,00252^{* *} T^{2} \\
\text { CÛ́D }=93713\end{array}$ & 0,95 \\
\hline \multirow{4}{*}{ G2 } & $1 \mathrm{E3A}$ & CÔD $=99,214-0,0488^{*} T$ & 0,82 \\
\hline & 2E2A & CÛD $=97,002+0,166^{* *} T-0,00316^{* *} T^{2}$ & 0,99 \\
\hline & 3E1A & CÛD $=96,483+0,281^{* *} T-0,00498^{\star *} T^{2}$ & 0,98 \\
\hline & $4 \mathrm{E}$ & CÛD $=100,389-0,0912^{* *} T-0,00142^{*} T^{2}$ & 0,79 \\
\hline \multirow{4}{*}{ G3 } & $1 \mathrm{E3A}$ & CÛ́D $=93,791$ & \\
\hline & $2 \mathrm{E} 2 \mathrm{~A}$ & CÛD $=93,600+0,233^{\star *} T-0,00387^{\star *} T^{2}$ & 0,97 \\
\hline & 3E1A & CÛD $=96,352+0,0156^{\text {ns }} T-0,00230^{* *} T^{2}$ & 0,96 \\
\hline & $4 \mathrm{E}$ & CÛD $=94,623$ & \\
\hline
\end{tabular}

O modelo quadrático foi o que melhor representou a relação entre os dados de CUD e o tempo de funcionamento das subunidades dotadas do gotejador G1 submetidas aos manejos 1E3A, 2E2A e 3E1A, sendo os valores de $\mathrm{R}^{2}$ de 0,$98 ; 0,91$ e 0,95 , respectivamente; no entanto, na subunidade submetida ao manejo $4 \mathrm{E}$ não se constatou efeito significativo do tempo de funcionamento na alteração do CUD.

Observou-se que o modelo linear foi o que melhor representou a relação entre os dados de CUD e o tempo de funcionamento da subunidade dotada do gotejador G2 submetida ao manejo $1 \mathrm{E} 3 \mathrm{~A}$, tendo $\mathrm{R}^{2}$ de 0,82 ; entretanto, o modelo quadrático foi o que melhor representou a relação entre os dados de CUD e o tempo de funcionamento das subunidades submetidas aos manejos 2E2A, 3E1A e 4E, sendo os valores de $\mathrm{R}^{2}$ de 0,$99 ; 0,98$ e 0,79 , respectivamente.

OCUD das subunidades dotadas do gotejador G3 submetidas aos manejos $1 \mathrm{E} 3 \mathrm{~A}$ e $4 \mathrm{E}$, não foi alterado significativamente pelo tempo de funcionamento; entretanto, o modelo quadrático foi o que melhor se ajustou aos dados de CUD em função do tempo de funcionamento das subunidades submetidas aos manejos $2 \mathrm{E} 2 \mathrm{~A}$ e 3E1A, sendo os valores de $\mathrm{R}^{2}$ de 0,97 e 0,96 , respectivamente.

Variações significativas de decréscimo do CUD em relação ao tempo de avaliação de sistema de irrigação localizada também foram observadas por Batista et al. (2010) em estudos avaliando a influência da aplicação de esgoto doméstico tratado via gotejamento; após $120 \mathrm{~h}$ de funcionamento foram verificadas reduções nos valores do CUD, da ordem de 10,58\%. Os mesmos autores atribuem a redução do CUD ao entupimento parcial ou total dos gotejadores ocasionado pela formação de um biofilme, resultante da interação entre colônias de bactérias e algas.
O entupimento de emissores é um grave problema associado ao gotejamento, visto que dificulta a operação de sistemas de irrigação, é de difícil detecção e a limpeza ou substituição dos emissores entupidos, é onerosa (Vieira et al., 2004).

Estão apresentados, na Tabela 5, os valores médios da variável CUD para o fator gotejador dentro de cada nível de tempo de funcionamento e cada manejo de água. Constata-se, neste quadro, que não houve efeito do manejo de água sobre o CUD, para cada tipo de gotejador, até o tempo de funcionamento de $60 \mathrm{~h}$.

Tabela 5. Valores médios da variável coeficiente de uniformidade de distribuição (CUD - \%) para o fator gotejador dentro de cada nível de tempo de funcionamento e cada manejo de água residuária e água de abastecimento

\begin{tabular}{|c|c|c|c|c|c|}
\hline \multirow{2}{*}{$\begin{array}{c}\text { Tempo } \\
\text { (h) }\end{array}$} & \multirow{2}{*}{ Gotejador } & \multicolumn{4}{|c|}{ Manejos de água } \\
\hline & & 1E3A & 2E2A & 3E1A & $4 \mathrm{E}$ \\
\hline \multirow{3}{*}{0} & G1 & $97,05 \mathrm{Aa}$ & $97,40 \mathrm{Aa}$ & $97,58 \mathrm{Aa}$ & $97,93 \mathrm{Aa}$ \\
\hline & G2 & $97,51 \mathrm{Aa}$ & $97,89 \mathrm{Aa}$ & $98,14 \mathrm{Aa}$ & $98,05 \mathrm{Aa}$ \\
\hline & G3 & $95,97 \mathrm{Aa}$ & $95,52 \mathrm{Aa}$ & $95,79 \mathrm{Aa}$ & $94,64 \mathrm{Aa}$ \\
\hline \multirow{3}{*}{20} & G1 & $97,42 \mathrm{Aa}$ & $97,27 \mathrm{Aa}$ & $97,31 \mathrm{Aa}$ & $96,60 \mathrm{Aa}$ \\
\hline & G2 & $97,94 \mathrm{Aa}$ & $97,82 \mathrm{Aa}$ & $97,90 \mathrm{Aa}$ & $98,42 \mathrm{Aa}$ \\
\hline & G3 & $95,49 \mathrm{Aa}$ & $94,67 \mathrm{Aa}$ & $95,05 \mathrm{Aa}$ & $94,23 \mathrm{Aa}$ \\
\hline \multirow{3}{*}{40} & G1 & $96,87 \mathrm{Aa}$ & $96,85 \mathrm{Aa}$ & $95,44 \mathrm{Aa}$ & $89,73 \mathrm{Aa}$ \\
\hline & G2 & $97,00 \mathrm{Aa}$ & $96,39 \mathrm{Aa}$ & $96,66 \mathrm{Aa}$ & $93,01 \mathrm{Aa}$ \\
\hline & G3 & $95,66 \mathrm{Aa}$ & $93,61 \mathrm{Aa}$ & $92,00 \mathrm{Aa}$ & $95,75 \mathrm{Aa}$ \\
\hline \multirow{3}{*}{60} & G1 & $96,12 \mathrm{Aa}$ & $95,21 \mathrm{Aa}$ & $93,47 \mathrm{Aa}$ & $92,89 \mathrm{Aa}$ \\
\hline & G2 & $97,63 \mathrm{Aa}$ & $97,31 \mathrm{Aa}$ & $97,13 \mathrm{Aa}$ & $95,73 \mathrm{Aa}$ \\
\hline & G3 & $95,12 \mathrm{Aa}$ & $93,83 \mathrm{Aa}$ & $91,93 \mathrm{Aa}$ & $93,59 \mathrm{Aa}$ \\
\hline \multirow{3}{*}{80} & G1 & $94,76 \mathrm{Aa}$ & $87,98 \mathrm{Aa}$ & $68,74 \mathrm{Bb}$ & $94,41 \mathrm{Aa}$ \\
\hline & G2 & $97,09 \mathrm{Aa}$ & $92,84 \mathrm{Aa}$ & $91,41 \mathrm{Aa}$ & $87,32 \mathrm{Aa}$ \\
\hline & G3 & $92,96 \mathrm{Aa}$ & $90,80 \mathrm{Aa}$ & $86,62 \mathrm{Aa}$ & $95,28 \mathrm{Aa}$ \\
\hline \multirow{3}{*}{100} & G1 & $89,11 \mathrm{Aa}$ & $62,09 \mathrm{Bb}$ & $56,55 \mathrm{Bb}$ & $92,96 \mathrm{Aa}$ \\
\hline & G2 & $95,53 \mathrm{Aa}$ & $82,77 \mathrm{Ab}$ & $76,31 \mathrm{Ab}$ & 84,66 Aab \\
\hline & G3 & $93,76 \mathrm{Aa}$ & $84,63 \mathrm{Aab}$ & $77,30 \mathrm{Ab}$ & $93,56 \mathrm{Aa}$ \\
\hline \multirow{3}{*}{120} & G1 & $80,16 \mathrm{Bb}$ & $21,23 \mathrm{Bc}$ & $32,87 \mathrm{Bc}$ & $94,86 \mathrm{Aa}$ \\
\hline & G2 & $93,51 \mathrm{Aa}$ & $68,35 \mathrm{Ab}$ & $57,70 \mathrm{Ab}$ & $45,98 \mathrm{Bc}$ \\
\hline & G3 & $91,57 \mathrm{Aa}$ & $61,43 \mathrm{Ab}$ & $56,62 A b$ & $95,21 \mathrm{Aa}$ \\
\hline \multirow{3}{*}{140} & G1 & $73,92 \mathrm{Bb}$ & $15,99 \mathrm{Cc}$ & $16,72 \mathrm{Cc}$ & $93,24 \mathrm{Aa}$ \\
\hline & G2 & $91,88 \mathrm{Aa}$ & $56,51 \mathrm{Ab}$ & $30,47 \mathrm{Bc}$ & $65,01 \mathrm{Bb}$ \\
\hline & G3 & $92,73 \mathrm{Aa}$ & $43,83 \mathrm{Bb}$ & $51,35 \mathrm{Ab}$ & $95,38 \mathrm{Aa}$ \\
\hline \multirow{3}{*}{160} & G1 & $69,57 \mathrm{Bb}$ & $13,08 \mathrm{Bc}$ & $17,49 \mathrm{Bc}$ & $90,79 \mathrm{Aa}$ \\
\hline & G2 & $89,69 \mathrm{Aa}$ & $44,55 \mathrm{Ab}$ & $18,78 \mathrm{Bc}$ & $54,00 \mathrm{Bb}$ \\
\hline & G3 & $90,86 \mathrm{Aa}$ & $36,29 \mathrm{Ab}$ & $44,38 \mathrm{Ab}$ & $94,00 \mathrm{Aa}$ \\
\hline
\end{tabular}

* Médias seguidas de pelo menos uma mesma letra maiúscula nas colunas para cada tempo de funcionamento e minúscula nas linhas para cada manejo de água não diferem entre si, a 0,05 de probabilidade, pelo teste de Tukey

Comparando as médias da variável CUD seguidas de pelo menos uma mesma letra maiúscula nas colunas da Tabela 5 , verificou-se que: no manejo $1 \mathrm{E} 3 \mathrm{~A}$, a partir de $120 \mathrm{~h}$, o CUD da subunidade dotada do gotejador G1 diferiu do CUD das subunidades com gotejadores G2 e G3; no manejo 2E2A o CUD da subunidade com gotejador G1 diferiu do CUD das subunidades dotadas dos gotejadores G2 e G3, nos tempos de funcionamento de 100, 120 e $160 \mathrm{~h}$; enquanto os valores de CUD das subunidades com gotejadores G1, G2 e G3 diferiram entre si no tempo de funcionamento de $140 \mathrm{~h}$; no manejo 3E1A o CUD da subunidade com gotejador G1 diferiu do CUD das subunidades dotadas dos gotejadores G2 e G3 nos tempos de funcionamento de 80,100,120 e $160 \mathrm{~h}$; contudo os valores de CUD das subunidades com gotejadores G1, G2 e G3 diferiram entre si no tempo de funcionamento de $140 \mathrm{~h}$ e no manejo $4 \mathrm{E}$, a 
partir de 120 h, o CUD da subunidade com gotejador G2 diferiu do CUD das subunidades dotadas dos gotejadores G1 e G3.

Analisando as médias da variável CUD seguidas de pelo menos uma mesma letra minúscula nas linhas da Tabela 5, observou-se que: no tempo de funcionamento de $80 \mathrm{~h}$ o CUD da subunidade com gotejador G1, submetida ao manejo 3E1A, diferiu do CUD das subunidades submetidas aos manejos 1E3A, 2E2A e $4 \mathrm{E}$.

No tempo de funcionamento $100 \mathrm{~h}$ o CUD das subunidades dotadas dos gotejadores G1, submetidas aos manejos 1E3A e 4E, diferiu do CUD das subunidades submetidas aos manejos 2E2A e 3E1A, o CUD das subunidades com gotejador G2 submetidas ao manejo 1E3A, diferiu do CUD das subunidades submetidas aos manejos 2E2A e 3E1 A e o CUD das subunidades com gotejador $\mathrm{G} 3$ submetidas aos manejos $1 \mathrm{E} 3 \mathrm{~A}$ e $4 \mathrm{E}$, diferiu do CUD da subunidade submetida ao manejo 3E1A.

No tempo de funcionamento de $120 \mathrm{~h}$, os valores de CUD das subunidades dotadas dos gotejadores G1 e G2, submetidas aos manejos 1E3A, 2E2A e 4E, diferiram entre si; enquanto o CUD das subunidades com gotejador G3, submetidas aos manejos 1E3A e 4E, diferiu do CUD das subunidades submetidas aos manejos 2E2A e 3E1A.

Nos tempos de funcionamento de 140 e $160 \mathrm{~h}$ os valores de CUD das subunidades dotadas dos gotejadores G1 e G2 submetidas aos manejos 1E3A, 3E1A e 4E, diferiram entre si enquanto o CUD das subunidades com gotejador G3 submetidas aos manejos 1E3A e 4E diferiu do CUD das subunidades submetidas aos manejos 2E2A e 3E1A.

Para Rezende et al. (2000) o bom desempenho do modelo de um tipo de gotejador submetido a suscetibilidade ao entupimento pela causa biológica, foi atribuído ao fato do elevado tamanho da área de filtragem de água, assim, como às características de fluxo e ao pequeno comprimento do percurso da água no interior do emissor.

Constatou-se, também, que os manejos 1E3A e $4 \mathrm{E}$ minimizaram o entupimento dos gotejadores; enquanto os manejos 2E2A e 3E1A o potencializaram. No manejo 1E3A, o tempo de aplicação de água foi maior em relação aos demais, passível de ter causado a remoção de sólidos do interior dos gotejadores e das linhas laterais ou até mesmo a redução da adesão microbiana nas paredes do equipamento acarretando, assim, a atenuação do entupimento. Em relação ao manejo 4E a minimização do entupimento pode ser atribuída à escassez de oxigênio dissolvido no efluente que, provavelmente, diminuiu a produção de subprodutos da atividade microbiana e, em contrapartida, a formação de biofilme. Nos manejos 2E2A e 3E1A os menores tempos de aplicação de água não foram suficientes para remoção dos sólidos do interior do equipamento, além de favorecer o desenvolvimento do biofilme, devido ao fornecimento de oxigênio dissolvido aos microorganismos aeróbios.

Para Vieira et al. (2004) vários fatores podem comprometer a uniformidade de distribuição de água em sistemas localizados destacando-se, entre eles, o entupimento ou o desequilíbrio de vazão dos emissores causado pelas partículas minerais ou orgânicas presentes na água; salienta-se também que nos sistemas por gotejamento a água escoa por pequenos bocais podendo causar sua obstrução em virtude da deposição de materiais em suspensão. Batista et al. (2010) verificaram que o entupimento de gotejadores foi mais acentuado no final das linhas laterais; portanto, uma prática que pode ser adotada para redução desse tipo de problema é a abertura do final dessas linhas ao início dos eventos de irrigação.

\section{Conclusões}

1. Na água residuária de suinocultura as características sólidos suspensos, ferro total e população bacteriana, representaram risco severo de entupimento de gotejadores.

2. A formação de biofilme foi maior no gotejador G1 em relação a G2 e G3, quando operados com distintos manejos de água residuária de suinocultura e de água de abastecimento.

3. Os níveis de entupimento dos gotejadores G1, G2 e G3 podem ser menores em função do menor tempo de funcionamento do equipamento para aplicação sustentável da água residuária da suinocultura.

4. Houve redução elevada da uniformidade de aplicação de efluente quando o tempo de aplicação de água residuária de suinocultura foi igual ou superior ao da água de abastecimento, favorecendo o desenvolvimento de biofilme.

\section{Agradecimentos}

Os autores agradecem ao Conselho Nacional de Desenvolvimento Científico e Tecnológico $(\mathrm{CNPq})$ pelo apoio financeiro em prol do desenvolvimento da pesquisa.

\section{Literatura Citada}

APHA - American Public Health Association. Standard methods for the examination of water and wastewater. 21.ed. Washigton: APHA, AWWA, WEF, 2005. 1268p.

Batista, R. O.; Matos, A. T.; Cunha, F. F.; Monaco, P. A. lo. Obstrução de gotejadores utilizados para a aplicação de água residuária da despolpa dos frutos do cafeeiro. Irriga, v.10, p.299-305, 2005.

Batista, R. O.; Soares, A. A.; Marin, O. L. Z.; Souza, J. A. R.; Sartori, M. A.; Oliveira Batista, R. Eficiencia del tratamiento químico em La prevención del taponamiento de goteros aplicando agua residual sanitaria tratada. Dyna, v.76, p.149157, 2009.

Batista, R. O.; Souza, J. A. R.; Ferreira, D. C. Influência da aplicação de esgoto doméstico tratado no desempenho de um sistema de irrigação. Revista Ceres, v.57, p.18-22, 2010.

Cabral, J. R.; Freitas, P. S. L.; Rezende, R.; Muniz, A. S.; Bertonha, A. Impacto da água residuária de suinocultura no solo e na produção de capim-elefante. Revista Brasileira de Engenharia Agrícola e Ambiental, v.15, p.823-831, 2011.

Capra, A.; Scicolone, B. Water quality and distribution uniformity in drip/trickle irrigation systems. Journal of Agricultural Engineering Research, v.70, p.355-365, 1998.

Capra, A.; Scicolone, B. Emitter and filter tests for wastewater reuse by drip irrigation. Agricultural Water Management,v.68, p.135-149, 2004.

Cararo, D. C.; Botrel, T. A. Uso de cloração e ar comprimido no controle do entupimento de gotejadores. Engenharia Agrícola, v.27, p.336-345, 2007. 
Dazhuang, Y.; Zhihui, B.; Rowan, M.; Likun, G.; Shumei, R.; Peiling, Y. Biofilm structure and its influence on clogging in drip irrigation emitters distributing reclaimed wastewater. Journal of Environmental Sciences, v.21, p.834-841, 2009.

Drumond, L. C. D.; Zanini, J. R.; Fernandes, A. L. T.; Rodrigues, G. P. Uniformidade de distribuição superficial e subsuperficial de água e de água residuária de suinocultura com irrigação por aspersão em malha. Engenharia Agrícola, v.26, p.415-425, 2006.

Duran-Ros, M.; Puig-Bargues, J.; Arbat, G.; Barragan, J.; Ramirez De Cartagena, F. Effect of filter, emitter and location on clogging when using effluents. Agricultural Water Management, v.96, p.67-79, 2009.

Lemos Filho, M. A. F.; Zanini, J. R.; Silva, E. R. S.; Cazetta, J. O.; Ferraudo, A. S. Sistema com aeração, decantação e filtragem para a melhoria da qualidade de água em irrigação localizada. Engenharia Agrícola, v.31, p.506-519, 2011.

Libânio, M. Fundamentos de qualidade e tratamento de água. Campinas: Átomo, 2005. 444p.

Liu, H.; Huang, G. Laboratory experiment on drip emitter clogging with fresh water and treated sewage effluent. Agricultural Water Management, v.96, p.745-756, 2009.

López, J. R.; Abreu, J. M. H.; Regalado, A. P.; Hernandez, J. F. G. Riego localizado. Madrid: Mundi-Prensa,1992, 405p.

Maggi, C. F; Freitas, P. S. L. de; Sampaio, S. C. E.; Dieter, J. Lixiviação de nutrientes em solo cultivado com aplicação de água residuária de suinocultura. Revista Brasileira de Engenharia Agrícola e Ambiental, v.15, p.170-177, 2011.

Merriam, J. L.; Keller, J. Farmirrigation system evaluation: A guide for management. Logan: Utah State University, 1978. 271p.

Nakayama, F. S.; Bucks, D. A. Water quality in drip/trickle irrigation: A review. Irrigation Science, v.12, p.187-192, 1991.
Puig-Bargués, J.; Arbat, G.; Barragán, J.; Cartagena, F. R. de. Hydraulic performance of drip irrigation subunits using WWTP efluents. Agricultural Water Management, v.77, p.249-262, 2005.

Puig-Bargués, J.; Arbat, G.; Elbana, M.; Duran-Ros, M.; Barragán, J.; Ramírez De Cartagena, F.; Lamm, F. R. Effect of flushing frequency on emitter clogging in microirrigation with effluents. Agricultural Water Management, v.97, p.883891, 2010.

Rezende, R. S.; Coelho, R. D.; Piedade, S. M. de S. Suscetibilidade de gotejadores ao entupimento de causa biológica. Revista Brasileira de Engenharia Agrícola e Ambiental, v.4, p.368-375, 2000.

Ribeiro Júnior, J. I.; Melo, A. L. P. Guia prático para utilização do SAEG. Viçosa: UFV, 2008. 288p.

Santos, C. G. F.; Lima, V. L. A. de; Matos, J. de A.; Haandel, A. C. van; Azevedo, C. A. V. de. Efeito de uso de águas residuárias sobre a vazão de microaspersores. Revista Brasileira de Engenharia Agrícola e Ambiental, v.7, p.577580, 2003.

Silva, L. P.; Silva, M. M.; Correa, M. M.; Souza, F. C. D.; Silva, E. F. F. Desempenho de gotejadores autocompensantes com diferentes efluentes de esgoto doméstico. Revista Brasileira de Engenharia Agrícola e Ambiental, v.16, p.480-486, 2012.

Souza, J. A. A.; Cordeiro, E. A.; Costa, E. L. Aplicação de hipoclorito de sódio para recuperação de gotejadores entupidos em irrigação com água ferruginosa. Revista Brasileira de Engenharia Agrícola e Ambiental, v.10, p.59, 2006.

Vieira, G.H.S.; Mantovani, E.C.; Silva, J.G.F.; Ramos, M.M.; Silva, C.M. Recuperação de gotejadores obstruídos devido à utilização de águas ferruginosas. Revista Brasileira de Engenharia Agrícola e Ambiental, v.8, p.1-6, 2004. 